\title{
Public Health Students' Reflection regarding the First Case of Coronavirus Disease 2019 in a University, Southern Thailand
}

Suwanbamrung $\mathrm{C}^{1^{*}}$, Kaewsawat $\mathrm{S}^{1}$

${ }^{1}$ School of Public Health, Walailak University, Nakhon Si Thammarat, Thailand

Corresponding Author: Charuai Suwanbamrung, RN, MSN, NP, APN, PhD. ${ }^{\text {ORCID ID }}$

Address: Assoc. Prof. Dr. in School of Public Health, and the Excellent Center for Dengue and Community Public Health (EC for DACH), Walailak University, Nakhorn Si Thammarat Province, 80161, Thailand; Tel: +66-7567-2101; Fax: +667567-2103; Email: Scharuai@wu.ac.th; yincharuai@gmail.com

Received date: 21 September 2020; Accepted date: 23 October 2020; Published date: 30 October 2020

Citation: Suwanbamrung C, Kaewsawat S. Public Health Students' Reflection regarding the First Case of Coronavirus Disease 2019 in a University, Southern Thailand. J Health Care and Research. 2020 Oct 30;1(3): 182-92.

Copyright (C) 2020 Suwanbamrung C, Kaewsawat S. This is an open-access article distributed under the Creative Commons Attribution License, which permits unrestricted use, distribution, and reproduction in any medium, provided the original work is properly cited.

\section{Abstract}

Background: The coronavirus disease 2019 (COVID-19) is a pandemic disease. In Thailand, public health professionals are the main stakeholder for risk management. The aim was to explore the reflections of the public health students regarding the first case of a COVID-19 patient near a university area, southern Thailand.

Study design: The cross-sectional qualitative study

Methods: The study was conducted written on one page which contained four elements of the reflection concept. Students' reflections were collected by the researcher after oral consent. The data analysis used the thematic analysis technique and included the following five steps: 1) reading and rereading to understand reflections, 2) identifying the coding, 3) setting the category of the coding in relation to meanings, 4) interpreting the theme based on their meaning and related phenomena, and 5) setting the main themes.

Results: Ninety public health students that studied at a $3^{\text {rd }}$ level classification of a community public health program. Almost all (77) were women (85.6\%), were 20-21 years old, and had received information regarding the coronavirus outbreak from social media, family members, other students, lecturers, and other people. The 17 themes and 35 sub-themes of the reflection concept included three themes' regarding the seven sub-themes of "What I faced", five themes regarding the six sub-themes of "What I did", four themes regarding the seven sub-themes of "What Happened", and five themes regarding the 19 sub-themes of "So what or now what" elements.

Conclusions: The reflections of the public health students are important for lecturers, the university, and their parents for supporting and guiding them to prevent the transmission of COVID-19.

\section{Keywords}

Reflection, COVID-19, Qualitative Study, Public Health Student 


\section{Introduction}

The Coronavirus Disease 2019 (COVID-19) is a disease caused by a coronavirus $(\mathrm{CoV})$ that severe cases can be death [1]. There could be many more undetected and unconfirmed cases both in Thailand and abroad. The Thai MoPH announced that asymptomatic travelers arriving from at-risk countries and areas are strongly recommended to "selfquarantine" at home or another residence for 14 days. Persons arriving from out site countries are defined as disease infected zones with COVID-19 outbreaks, will face legal implications under the communicable diseases act if they do not follow the measures announced by the Royal Thai Government [1]. The Thai MoPH (as of the $6^{\text {th }}$ March 2020) reported four new local coronavirus disease (COVID-19) cases - men aged 20-42 years who arrived from Iran and Italy in the past week. The fourth is a Thai student, age 20 who returned from Iran. Five days later, he went to a district hospital with a fever and runny nose. The patient stays at home near the university area which all students knew the COVID-19 patient was visiting in the university's area.

The impact of the pandemic and the danger from the disease has caused the emotion of fear. The definition of "fear" is the response to a certain stimulus occurring in the present or the anticipation or expectation of a future threat perceived as a risk to oneself. The fear response arises from the perception of danger leading to a confrontation with or escapes from/avoiding the threat, which in extreme cases can be a freeze response or paralysis. The symptoms of general anxiety disease (GAD) may include restlessness, uncontrollable feelings of worry, increased irritability, difficulty concentrating, and difficulty sleeping [2]. However, some people showed very strong feelings of anxiety or fear regarding COVID-19 infection, which are associated with the definition of panic as overwhelming feelings of anxiety and frantic agitation reactions [3,4]. Several people are aware of COVID-19. What do they do in daily life in a crisis situation? Are they ready to quickly respond to a possibly dangerous situation from COVID-19? How do we understand human experiences?
Reflection was defined by John Dewey (as cited in Cotton) [5] as the '...active, persistent and careful consideration of any belief or supposed form of knowledge...', and Mezirow cited in Chong defined reflection as associated with relationship and to individual needs and to larger extent emotional and personal feelings that have impacted on the intellectual reflective learning [6]. Reflective learning is of particular relevance to the education of professionals since it encourages students to integrate theory with practice, appreciate the world on their own behalf, and turn every experience into a new potential learning experience [7]. In terms of learning, 'The learning cycle development is based on the belief that learning of real comprehension comes from a sequence of experience, reflection, and active testing as well as the function of the brain'. A study suggested the reflection concept was important for health promotion [8].

The phenomenological approach is a type in qualitative method focusing on understanding and describing the human experience [9]. An investigative approach was used to understand the lived experience and human experience through reflections because reflection can be used as a method or tool that connects knowledge and experiences [10]. One study focused on the phenomenological approach, namely, travelers' experience when they return home, such as travel health behaviors, dengue prevention, and mosquito avoidance practices. The results of the interview using semi-structured open-end questionnaires showed the culturally embedded, risk perception of health, and the dengue disease's risk perception influenced travel behavior [11]. This study did not show regarding COVID-19 in public health students.

As mentioned above, few studies have used the phenomenological approach of reflection to prevent and control COVID-19 during the outbreak. We used students because they will be the public health providers in communities and will have roles in the prevention and control of communicable diseases in the future. We were the questions that what are the reflections of the public health students at a university in southern Thailand regarding preventing and controlling COVID-19? Then, this study aimed to 


\section{Original Article}

explore the reflections of public health students' experience related to COVID-19 prevention based on their experience.

\section{Methodology}

\section{Concept of Reflection:}

There are many models of reflection such as the North Carolina Teacher Reflection Model, the Gibbs Model of Reflection, and the Cognitive Affective Psychomotor: CAP Model of What? So What? Now What? [6,12]. Reflection is related with learning and assessment because reflection uses forms of structured reflection to improve the way humans learn. Learning/process portfolios were an original concept until Plato's directive "know thyself", which can lead to a lifetime of investigation [13,14]. They describe the primary motive of a learning portfolio as 'to improve student learning by providing a structure for students to reflect systematically overtime on the learning process and to develop the aptitudes, skills, and habits that come from critical reflection'.

In this sense, reflection can be likened to a bridge between theory and practice and a powerful means of using theory to inform practice. The concept of this study was applied to four elements [15]: 1) the situation/phenomena that describe "What I faced"; 2) the practice/action in which students need to show their activities as "What I did"; 3) the results of their actions, which are "What happened"; and 4) the reflection on the results/events such as innovation, creativity, critical thinking, communication, etc. and the actions in the future reflecting the meaning of these reflections in the form of "So what or now what" (Fig-1).

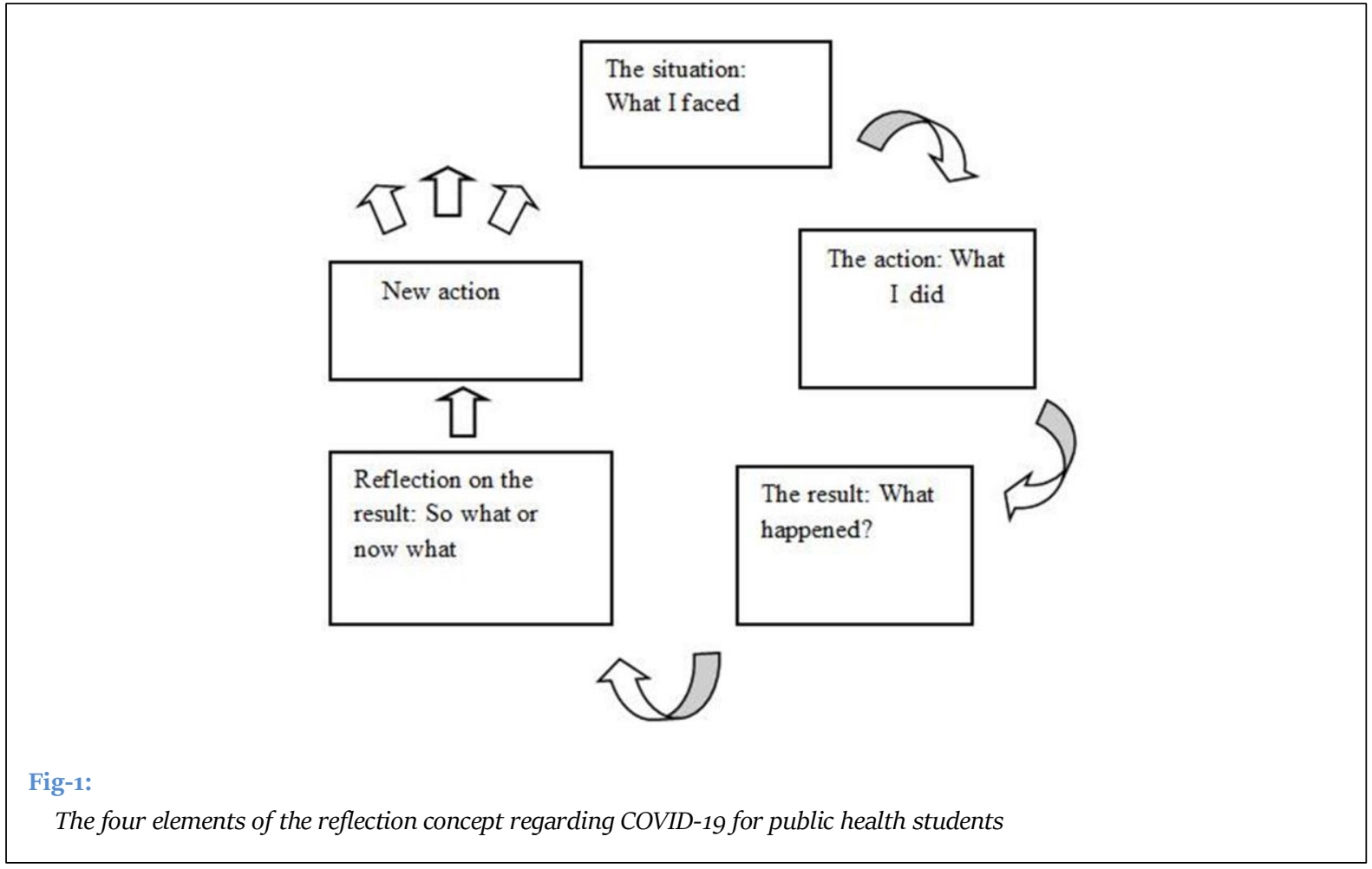

\section{Study Design:}

This qualitative study used a phenomenological approach, which claims that individuals with close proximity to the environment will experience certain phenomena. Phenomenology relies on latent observations to understand the situation based on the underlying features. Natural phenomenology focuses on the belief that the method will shed light on personal knowledge and perceptions to uncover the lived experiences. Thus, phenomenology will be different based on an individual's experience [16], and the experience of all stakeholders involved with COVID-19 may be different, necessitating the study of the experiences of community public health students.

\section{Data Collection:}

The researcher enrolled public health students as 
participants based on the description of the research's objectives; collected informed, oral consent; and facilitated the participants' reflections on their views and experience with COVID-19. Because the reflections were defined as being associated with relationships and individual needs, they were emotional and personal feelings that have impacted intellectual reflective learning. The study used the reflection technique of personal experience [15]. The data on the community of public health students' reflections from their perceptions were collected on one A4-sized page regarding the following: the COVID-19 outbreak situation (What I faced), their preventative actions (What I did), the results from their activities (What happened or the results), and their new behavior or their learning (So what or now what).

\section{Data Analysis:}

Most of the data analysis in the qualitative study used thematic analysis [11,17-19]. The thematic structure of a lived experience describes the phenomena in question [20]. The data analysis in this study used the thematic analysis technique and included the following five steps: 1) reading and rereading to understand the content of the reflections, 2) identifying the coding, 3) setting the category or sub-theme of the coding in relation to their meanings, 4) interpreting the theme based on their meaning and related phenomena, and 5) setting the main themes.

\section{Trustworthiness:}

At the end of data analysis, the researcher presented the results to the same representative participants so they could thematically review the interpretation. This technique is the most important one to establish a study's credibility [21]. Thus, the participants were asked to validate the thematic and general description of their reflections after the preliminary interpretation.

\section{Results}

There were 90 public health students who studied at the $3^{\text {rd }}$ level classification of a community public health program at a school of public health in a university in southern Thailand. Almost all (77) were women (85.6\%), were 20-21 years old, and received information regarding the COVID-19 pandemic from social media, family members, other students, lecturers, and other people. The themes of students' reflections presented 17 themes.

\section{The Situation: What I Faced:}

What did public health students face during the COVID-19 situation? Ninety public health students reflected on the COVID-19 situation through their experiences regarding the situation. The students' reflections in this section were used to identify the 186 codes, and seven sub-themes (Supplement-1), and three themes such as:

1. COVID-19 is the most dangerous disease for all peoples in the world, countries, and my university represents that students have been monitoring the COVID-19 situations such as the morbidity rate, mortality rate, and outbreaks in several areas around the world, in different countries, in Thailand, and in their local areas. There are known dangers of COVID19 such as disease transmission, the signs and symptoms, the severity and prognosis, prevention and control methods, communication techniques, and the number of cases at their university. They perceived the danger of the disease that quickly transmits as a threat to their lives. A quote: '...have a severe outbreak in China and other countries including Thailand, which is infected with COVID-19 and increasing with four cases such as number one from Italy, number two from Thailand, number three from China, and number four from Thailand but came from a foreign country... especially case number four who stayed domiciled in the area near my university ...in total (as of $5{ }^{\text {th }}$ March 2020), Thailand has COVID-19 cases and a death'.

2. Known causes and signs and symptoms of COVID19 are important for public health student theme means they know that the cause of the coronavirus disease is zoonotic, meaning that it is transmitted between animals and people. Detailed investigations found that SARS-CoV was transmitted from civet cats to humans and MERS-CoV was transmitted from dromedary camels to humans. Several known coronaviruses are circulating in animals that have not yet infected humans. The students know the signs and symptoms of COVID-19, such as fever, cough, and shortness of breath, and breathing difficulties. In more severe cases, the infection can cause pneumonia, 
severe acute respiratory syndrome, kidney failure, and even death. A quote: '...having symptoms similar to influenza ...China showed the virus spreads rapidly in the respiratory system and found patients presented body temperature more than $37.5{ }^{\circ} \mathrm{C}$ cough, sore throat, weak and rapid breath, maybe some patients have diarrhea and spread from person to person through cough, sneeze, ...'.

3. Lack of personal protective equipment because of panic and alert situation to prevent COVID-19 infection theme means the students are unsure that the COVID19 outbreak will stop and someone may panic regarding COVID-19 or have anxiety or fear over COVID-19 infection. They were told by others to find personal protective equipment and that this equipment would be a higher price but lower quality than the necessary standard. A quote: '...everyone in Thailand uses surgical masks to prevent and protect against coronavirus infection, influencing the lack of availability, hard to find, and very expensive...'.

\section{The Action: What I Did:}

What did public health students do to prevent and control COVID-19? The reflections were analyzed into 154 codes, six sub-themes (Supplement-1), and five themes with different meanings as follows:

1. Preventing activities and alerts for seeking personal protection equipment for COVID-19 means the process of preventing COVID-19 by seeking personal protection equipment. A quote: ‘...Buy a surgical mask to put on to prevent COVID-19, carry a hand wash gel with alcohol $70 \%$, avoid using public areas at risk of virus, not traveling abroad, observing my health status...'.

2. Following news of COVID-19 in order to solve problems based on the situation means monitoring the day to day COVID-19 situations and methods for solving problems. Because the COVID-19 situation is unstable and significantly worsening every time, solving COVID-19 needs the correct information from the local, district, provincial, and national government departments. Moreover, we need the information on the COVID-19 situation from the World Health Organization (WHO). A quote: '...monitoring the outbreak of COVID-19...I try to search for correct information from Google and Social media'.

3. Communication for protecting themselves is important means that public health students need to communicate information on COVID-19 prevention and methods to solve the COVID-19 problems such as continuous monitoring to provide correct information, surgical mask shops, shops selling hand soap, correct hand washing techniques, and methods of contacting PUIs. A quote: '...have judgment regarding the monitoring of COVID-19 information...unbelievable fake news ...gave corrected information for all people in the community...'.

4. Surveillance and observation of the at-risk group of COVID-19 theme represent students' behaviors when searching, collecting, and analyzing the news on the at-risk COVID-19 groups from foreign countries who have contacted COVID-19 and PUIs for COVID-19. A quote: '...monitoring news tracking we feel that the disease is very close to the university...although we stay at southern, which is away from COVID-19 patient in Bangkok....decreasing activities with international students'.

5. Coping with feeling shocked, afraid, sad, and conscious means students were coping and managing the COVID-19 phenomena such as feelings shocked, afraid, sad, and conscious. There were different coping methods based on their emotions. A quote: '...lack of personal protective equipment (PPE) while there is news confirming that a case of COVID-19 case in the area near my university... I feel anxiety after hearing the news...'.

\section{The Result: What Happened?}

The data from the students' activities for solving COVID-19 were classified into 109 coding and 7 subthemes (Supplement-1) and four themes following:

1. COVID-19 outbreak increasing, then everyone must change behaviors was a theme that integrated the subtheme of Safety behaviors changing and Have COVID19 outbreak. The theme means that people were overwhelmed when finding the safe methods to prevent COVID-19 such as hand hygiene, masks for 
symptomatic individuals, the isolation and treatment of ill individuals, monitoring the symptoms of healthy contacts, traveler health advice, and environmental cleaning. They changed their behaviors in their daily lives. A quote: '...we must protect ourselves from coronavirus infection...avoid travel to risk areas of COVID-19, if we stay in a public place, we will put on a surgical mask every time, leave travel to risk countries, often hand washing...'.

2. If we need to decrease COVID-19 spread, we must set the guideline, personal protection equipment management, and correct communication is the theme analyzed from reflections with the three sub-themes such as Decreasing risk based on guidelines, Personal protection equipment management, and Communication was important. The theme means that the policy of the government that some people who come back from at-risk countries self-quarantine for 14 days did not guarantee that they would quarantine, and some suggested that people should self-quarantine as soon as they have signs and symptoms. The results for governments showed that there was a lack of personal protection equipment, the equipment had a high price of more than 10 times the normal price, and there was no available equipment to be bought. People were alert that they may have bought personal protection equipment due to wrong information such as fake news that everyone needs a surgical mask to protect themselves. However, COVID-19 would be decreasing because of the epidemiological stage, which needed several approaches. A quote 'finding a mask as the first thing in a panic situation... if I have the chance I will buy one using online shopping, and waiting to buy a surgical mask, 4 pieces per identified card...moreover, the price of the surgical mask is 10 times higher than usual'.

3. Decreasing quality of life theme represents students' reflections that their daily lifestyles have changed and they must carefully conduct their activities. They feel fear and anxiety regarding becoming infected by the coronavirus. The lifestyles of students were changed to stay at their dorms, avoid meeting with workgroups, travel everywhere in a personal car, and monitor the news for information regarding COVID-19. A quote: '...the outbreak of
COVID-19 makes me aware of increasing self-care and caution...if there are other disease outbreaks in the future, we will be increasing awareness...currently, I will be reserving food, surgical masks, hand wash gel, and other items....'.

4. Continuing surveillance theme represents the monitoring after students' activities to solve COVID-19. Their reflections showed that monitoring was important for all people. If they experience fever, coughs, and respiratory signs, they need to quarantine for 14 days. All students presented skills to observe themselves such as covering their coughs and sneezes with their sleeve or a tissue and not their hand, washing their hands thoroughly with soap and water, and staying home or at their dorm when they were sick. They need the university to provide the surveillance guidelines for COVID-19 prevention for all students and others who live at the university. A quote: '...people traveling to risky areas upon their return to Thailand to quarantine 14 days... observe people as PUI signs and symptoms such as fever, cough, and a sign of respiratory infection...if we found these signs, put on a surgical mask, often washing hands, and meet medical doctor stat...for general people, need to monitor signs and symptoms of themselves, practice prevention such as eat hot food, use own spoon, often hand washing, put on cotton mask ... continuous report of surveillance from government organizations'.

\section{Reflection of the Result: So What or Now What:}

So what with COVID-19's prevention and control of public health students had 109 codes, 19 sub-themes, and the five themes such as:

1. Personal awareness is the most important means that reflected on the activities of improved behavior, basic prevention, self-care, personal awareness, meeting with a medical doctor, proximity in their life, and washing hands as the best ways to protect themselves. A quote: '...the situation makes me aware of self-care and self-protection from COVID-19 such as put on a mask, washing hands... learning with the trend of morbidity rate, signs and symptoms, and mortality rate ... to prevent and control COVID-19'. 
2. People need to understand the signs of diseases means students acknowledge that learning about the disease, continued observation, people possessing knowledge regarding knowledge, and do not be careless are factors. A quote: '...learn to cope with the disease by having to know the signs and symptoms such as fever $>37.5{ }^{\circ} \mathrm{C}$, cough, sore throat, running nose, shortness of breath...observe and go to medical doctor...'.

3. The correct communication can solve problems means that reflected on the activities regarding COVID-19 news, were critical in listening news, did not conceal information, correctly added informationally, and acknowledged that concealing the news will have a high risk. A quote: '...communicate correct information, reduce the use of fake news without any sources... not believe news without defined sources, reduce the use of news in Twitter...'

4. Public health provider must take clear roles means the reflected on the activities regarding strict standards, panic, and anxiety, the role of public health providers, collaborative work, learning the risks and benefits, being good models for prevention and learning together. A quote: '...they should practice associated roles of public health providers such as health assessment, monitoring the at-risk group, basic health assessment of the at-risk group, disease surveillance for reducing transmission, education programs for prevention and control of COVID-19...'.

5. Social distancing is important in crisis situations means that reflected on the activities of being considerate to other humans, having a conscious mind, having social responsibility, and not taking COVID-19 lightly. A quote: “...social distancing, need to eat hot food, use own spoon, washing hands, staying home... if we have a fever, we should stay home, avoid crowds, use a surgical mask if we have cough or sneezing...don't take off the mask when we have a cough because others are afraid of dirty masks... in the situation of COVID-19, the responsibility to oneself and society the most important ...'.

\section{Discussions}

The 17 themes of the 90 students' reflections were classified into four issues like 1) What I faced, 2) What I did, 3) What happened, and 4) So what, and these included 3, 5, 4, and 5 themes, respectively. Several themes are taken from their experience as primarily 20-21 year olds and several channels of information such as received information regarding the coronavirus outbreak from the internet, family members, other students, lecturers, and other people. Moreover, the students in the study are included 77 women (85.6\%). Another result from 430 students showed that internet resources are the most commonly used and the search results in students find can affect their decision making and choices in treating sickness and promoting their health [22].

\section{The Situation (What I Faced):}

Their reflections showed three themes such as COVID-19 is the most dangerous situation for all peoples in the world, countries, and my university, Lack of personal protection equipment situation because of panic, and Alert situation to prevent COVID19 infection. The reflections showed the situation of COVID-19 among the students at the university is the most important as the coding of COVID-19 cases in their area $(27.4 \%)$ had the highest percentage, whereas the situation of lacking personal protection equipment $(4.3 \%)$ was the least frequent situation they faced. There was a COVID-19 case that stayed near their university on the day of their reflection. The case came from Iran [1], and a fake news story stated he went to the university. This situation was a concerning situation for all students. However, the personal protection equipment situation was the lowest concern because on the $6^{\text {th }}$ of March 2020 the COVID-19 situation of Thailand was at the start of an outbreak [1].

However, the theme Knowing causes and signs and symptoms of COVID-19 are important for public health students represented the situation of all students facing regarding the cause of the disease, its meaning, the signs and symptoms, and the method to prevent catching COVID-19. They are public health students that take the role of health providers after they graduate from the program, and currently, all students 
study health assessment and fundamental therapeutic subjects. The Thai Community Health Professions Act sets the standard for all public health professionals [23].

\section{The Action: What I did:}

This represents the activities of students for coping with the COVID-19 situation and what they did for COVID-19 prevention and control. We found that most reflections of students' activities were prevention activities and seeking personal protection equipment for COVID-19 prevention. It was common for people due to how the disease transmits between people. The situation was strongly influenced by their feelings such as how quickly the epidemic grows, when it peaks, its overall magnitude, and how long it lasts. It is associated with the following summary regarding infectious disease pandemic planning and response [24]. The students responded to the COVID-19 situation in five themes. The first theme is "Preventing activities and alert for seeking personal protection equipment for COVID-19". Their reflections are associated with the peoples' responses to those who are seriously unwell or die of the COVID-19. At the onset of the COVID-19 pandemic, Thailand $\left(6^{\text {th }}\right.$ March 2020) only had a few COVID-19 cases, and then most people did not clearly know COVID-19's pathogenesis, signs, symptoms, and treatments. Maybe they were feeling sub-themes that Coping with shocked, afraid, sad, and conscious feelings, Following news of COVID19 in order to solve problems based on the situation, Communications for protecting themselves are important, and Surveillance and observation of the atrisk group of COVID-19. Another review study regarding infectious disease pandemic planning and response showed that the pandemic response model needs social, political, and ethical considerations and decision making [25].

\section{The Result: What Happened?}

The outputs from the students' activities for solving COVID-19 were coded according to several key phrases. The percentages of their results were safety behaviors changing at $33.9 \%$, the belief that COVID-19 cases were increasing at $20.2 \%$, and Personal protection equipment management at $13.8 \%$. The results were related to the nature of the pandemic disease with increasing cases at the onset of the pandemic [24]. At this time ( $6^{\text {th }}$ March 2020), the Thai Ministry of Public Health (MoPH) announced one new case of COVID-19 [1]. After that, the morbidity and mortality rates were increasing and changing behaviors. Moreover, the theme If we need to decrease COVID-19, we must set the guideline, Personal protection equipment management, and Correct communication were associated with the available guidance for responding to the community transmission of COVID-19 [26].

Decreasing quality of life was a theme interesting result from their activities. Because there were cases, the local area near the university in southern Thailand was closed. All students were alert to the situation and sought to find masks and equipment to protect them from COVID-19. Some students feared showing physiological reactions in response to a perceived harmful event, attack, or threat to their survival from the person who contacted the fourth case [27] and experienced emotion-induced danger associated with the definition of "fear", which is the response to a certain stimulus occurring in the present or anticipation or the expectation of a future threat perceived as a risk to oneself. The fear responses arise from the perception of danger leading to a confrontation with or escape from/avoiding the threat, which in extreme cases of fear can be a freeze response or paralysis. Some students presented anxiety, where the symptoms of general anxiety disease (GAD) could include restlessness, uncontrollable feelings of worry, increased irritability, difficulty concentrating, and difficulty sleeping [2].

Moreover, the spread of COVID-19 is increasing as the pandemic spreads. The theme Continuing surveillance represented the clinical monitoring of the PUIs and the cases, transmission, quarantine, social distancing, and risk communication. The WHO proposed guidance for responding to the community spread of COVID-19 [26]. Standard recommendations to prevent its spread include regular hand washing, covering one's mouth and nose when coughing and sneezing, thoroughly cooking meat and eggs, and avoiding close contact with anyone showing symptoms of respiratory illness such as coughing and sneezing, this was done on 15 March 2020 [1]. 
Reflection of the Result: So What and Now What?

The concept of reflection is related with learning and assessment because reflection represents forms of structured reflection to improve the ways humans learn. Learning was an original concept until Plato's directive know themselves, which can lead to a lifetime of investigation [13,14]. We focused on the concept of so what or now what in the theme of innovation, creativity, critical thinking, communication, etc. and future actions. The most important category and key phrase Personal awareness is the most important. Then, they understood the signs and symptoms, and the method for prevention and control transmitting of disease, they would take the role as the themes. The theme People need to understand regarding the signs of diseases, and the correcting communication can solve problems that were focused on the students learning and understanding the knowledge and abilities to communicate as health providers because they have the role of public health providers. They need to take a role based on the theme Public health provider must take a clearing role, which a part of the health provider team.

The theme of Social distancing is important in a crisis situation was the top issue of Thailand. To stop the spread of COVID-19, everyone has practiced social distancing such as staying home, avoiding crowds and refraining from touching one another [26]. They learned about social distancing from the experience with the disease [28]. However, the World Health Organization (WHO) has characterized COVID-19 as a pandemic (The WHO declared COVID-19 a pandemic on 11 March 2020). In Thailand, the Thai MoPH states that COVID-19 is a dangerous communicable disease under the Communicable Disease Act of 2015 (B.E. 2558) ( $1^{\text {st }}$ March 2020), and gave the guidelines for COVID-19 (13 ${ }^{\text {th }}$ March 2020) [29]. All people learned the importance of 14-day quarantine and social distancing.

\section{Limitations}

The study is limited to the time (at 6th March 2020), the Thai Ministry of Public Health (MoPH) announced one new case of COVID-19. The results cannot refer in generalizability to other university populations because of the study focused on a very specific and small population within public health students; however, the study represents a basis for exploring the context and impact that culture may have on student behaviors. Future research should explore the COVID-19 phenomenon in other groups.

\section{Conclusion}

COVID-19 is a pandemic disease with increasing morbidity and mortality rates around the world. Southern Thailand has the same spread of the disease as other countries. The reflections of the public health students are important for lecturers, the university, and their parents for supporting and guiding them to prevent the transmission of COVID-19. Moreover, the university understood their experience and managed the course to reduce emotions and postpone the graduation program. The students will be able to apply their experience to manage communicable disease pandemics as health providers, and take roles in the prevention and control of communicable diseases.

\section{Acknowledgment}

I would like to sincerely thank you for the 90 reflections from the $3^{\text {rd }}$ year public health students, School of Public Health, Walailak University, and the Excellent Center for Dengue Research and Academic Service (EC for DRAS), Walailak University Thailand.

\section{Funding Statement}

This work was supported by the Excellent Center for Dengue Research and Academic Service (EC for DRAS), Walailak University under Grant [WU-COE-63004].

\section{Conflicts of Interest}

The author would like to report that she has no conflict of interest in the above work.

\section{References}

[1] WHO Thailand. Coronavirus disease 2019 (COVID19) WHO Thailand Situation Report - 6 March 2020. Thailand: World Health Organization; 2020 Mar 06. Available from: https://www.who.int/docs/defaultsource/searo/thailand/20200306-tha-sitrep-15-covid19-final-revision.pdf?sfvrsn=aob3719_o

[2] Felman A, Browne D. What to know about anxiety. 
Medical New Today; 2020 Jan 11. Available from: https://www.medicalnewstoday.com/articles/323454

[3] Gómez-Dantés H. El dengue en las Américas. Un problema de salud regional [Dengue in the Americas. A problem of regional health]. Salud Publica Mex. 1991 Jul-Aug;33(4):347-55. Spanish. [PMID: 1948410]

[4] Collins Dictionary. Panic. Collins; 2020. Available from:

https://www.collinsdictionary.com/dictionary/english /panic

[5] Cotton AH. Private thoughts in public spheres: issues in reflection and reflective practices in nursing. $\mathrm{J}$ Adv Nurs. 2001 Nov;36(4):512-19. [PMID: 11703545]

[6] Chong MC. Is reflective practice a useful task for student nurses? Asian Nurs Res (Korean Soc Nurs Sci). 2009 Sep;3(3):111-20. [PMID: 25030469]

[7] Wong FK, Kember D, Chung LY, Yan L. Assessing the level of student reflection from reflective journals. J Adv Nurs. 1995 Jul;22(1):48-57. [PMID: 7560535]

[8] Fleming P. Reflection a neglected art in health promotion. Health Educ Res. 2007 Oct;22(5):658-64. [PMID: 17071850]

[9] von Eckartsberg R. Introducing existentialphenomenological psychology New York: Plenum

Press; 1988.

[10] Tashiro J, Shimpuku Y, Naruse K, Maftuhah, Matsutani M. Concept analysis of reflection in nursing professional development. Jpn J Nurs Sci. 2013 Dec;10(2):170-79. [PMID: 24373440]

[11] Allen KC. Phenomenological analysis of going home in Caribbean-American international travelers. Trop Dis Travel Med Vaccines. 2015 Dec 20;1:12. [PMID: 28883943]

[12] Mann K, Gordon J, MacLeod A. Reflection and reflective practice in health professions education: a systematic review. Adv Health Sci Educ Theory Pract. 2009 Oct;14(4):595-21. [PMID: 18034364]

[13] Zubizarreta J. The Learning Portfolio. Bolton: Anker Publishing; 2004.

[14] Zubizarreta J. The learning portfolio: Reflective practice for improving student learning. John Wiley \& Sons; 2009 Dec 22.

[15] Suwanbamrung C. Learning experience of student nurses through reflection on clinical practice: A case study in pediatric nursing, Southern Thailand. Walailak Journal of Science and Technology (WJST). 2015 Jan 13;12(7):623-29.
[16] Laverty SM. Hermeneutic phenomenology and phenomenology: A comparison of historical and methodological considerations. Int J Qual Methods. 2003 Sep;2(3):21-35.

[17] Griffiths K, Banjara MR, O'Dempsey T, Munslow B, Kroeger A. Public health responses to a dengue outbreak in a fragile state: a case study of Nepal. J Trop Med. 2013;2013:158462. [PMID: 23690789]

[18] Stewart Ibarra AM, Luzadis VA, Borbor Cordova MJ, Silva M, Ordoñez T, Beltrán Ayala E, Ryan SJ. A social-ecological analysis of community perceptions of dengue fever and Aedes aegypti in Machala, Ecuador. BMC Public Health. 2014 Nov 4;14:1135. [PMID: 25370883]

[19] Respati T, Feriandi Y, Ndoen E, Raksanegara A, Djuhaeni H, Sofyan A, Dale P. A qualitative ecohealth model of dengue fever (DF) in Bandung, Indonesia. Int J Trop Dis. 2018;1(1):0o8.

[20] Christofi V, Thompson CL. You cannot go home again: A phenomenological investigation of returning to the sojourn country after studying abroad. J Couns Dev. 2007 Jan;85(1):53-63.

[21] Flick U, von Kardoff E, Steinke I, editors. A companion to qualitative research. Sage; 2004 May 25. [22] Dastani M, Mokhtarzadeh M, Nasirzadeh AR, Delshad A. Health information seeking behavior among students of Gonabad University of Medical Sciences. Library Philosophy and Practice (e-journal); 2019. Available from:

https://digitalcommons.unl.edu/libphilprac/2545

[23] The Thai Community Health Professions Act, B.E. 2556. (In Thai), 8. Sect. 118 (2020).

[24] Shearer FM, Moss R, McVernon J, Ross JV, McCaw JM. Infectious disease pandemic planning and response: Incorporating decision analysis. PLoS Med. 2020 Jan 9;17(1):e1003018. [PMID: 31917786]

[25] Bloom DE, Cadarette D. Infectious Disease Threats in the Twenty-First Century: Strengthening the Global Response. Front Immunol. 2019 Mar 28;10:549. [PMID: 30984169]

[26] WHO. Responding to community spread of COVID-19 Interim guidance. World Health Organization; 2020 Mar 7 [cited 202015 March]. Available from: https://www.who.int/thailand/healthtopics/coronavirus

[27] Cannon WB. The Wisdom of the Body. Nature. 1934 Jan 20;133:82. 


\section{Original Article}

[28] Cohen AK, Hoyt LT, Dull B. A Descriptive Study of COVID-19-Related Experiences and Perspectives of a National Sample of College Students in Spring 2020. J Adolesc Health. 2020 Sep;67(3):369-75. [PMID: 32593564]

[29] Department of Disease Control Thai Ministry of Public Health. Corona Virus Disease (COVID-19); 2020. Available from:

https://ddc.moph.go.th/viralpneumonia/eng/guideline s.php 